\title{
Traditional Ornaments of Lambadi and Koya Women
}

\author{
Godi Sindhu* and Shahnaz Jahan \\ Department of Clothing and Textiles, College of Home Science, G.B. Pant University of \\ Agriculture and Technology, Pantnagar, Uttarakhand, India \\ *Corresponding author
}

\begin{abstract}
A B S T R A C T
Keywords

Andhra Pradesh,

Lambdai, Koya, Female

ornaments, Gold, Silver

Article Info

Accepted:

07 October 2018

Available Online:

10 November 2018

South India is full of diversities in tribes, languages, traditions and customs. The tribal costumes will bring up a picture of the tribal life. Some of the traditional costumes are almost extinct with change of time. Therefore, a study was conducted in West Godavari and Krishna Districts of Andhra Pradesh, and an attempt has been made to restore the traditional ornaments of Lambadi and Koya tribes through documentation before it could get completely diminished. So that, one can geta detailed information regarding different traditional ornaments used by these tribes.
\end{abstract}

\section{Introduction}

The history of jewellery dated back many years ago, with different uses among different cultures and regions. It abided for thousands of years and provided numerous insights, how cultures work during the time of ancestors. All over the world, India is a multi-racial country with varied traditions and unique culture. Life style has been playing a significant role in identification of India since long time and the factors of identification may include food, clothing, ornaments, accessories and languages. In India, women are fond of jewellery and they wear it not only for looks and status, but also for good health.

Eventually, ornament was a marker of social value, endowing objects with dignity as in the decoration of sacred items for use in church ritual such as papal robes scepters, altarpieces etc, According to Nelson, 'ornament' is defined as something meant to honour it, to give it an elevated status and to make it something special. Thus ornaments are not so aesthetic, but amoral concept that involved the impregnation of an object with not just physical beauty but virtue. Ornament was a representation for good things, which are appropriate and valuable in a social sense. (Nelson, 1993)

\section{Materials and Methods}

Tribal Jewelry is both functional and empirical. Every tribe will have their unique style of ornaments intact even now and the indigenous identity of ornament design has 
been preserved by ethnic tribal with tremendous responsibility. It is not only beautiful, but often communicates messages about the wearer's status, spiritual beliefs, functional habits and wealth. It also marks communal celebrations, group association, and individual means of access. (Dwivedi, 2016)

The present study was based on primary data collected through the documentation of costumes and textiles of Lambadi and Koya tribes and secondary data like books and museums. The Lambadi and Koya women were interrogated with different questions related to Tribal Ornaments, material used, way of wearing, and their significance.

\section{Results and Discussion}

This study is based on secondary data. Materials of this article have been taken from relevant books, journals and articles.

The methods used are descriptive and analytical. The prime focus of the present study is to analyze the significance of metals used for jewellery along with spiritual, ethnic and traditional significance of religious jewellery. The materials used have at times been drawn from the website and extreme care has been taken to be objective in approach.

\section{Female ornaments}

The females of Lambadi and Koya tribe were very fond of ornaments and had variety of ornaments for different parts of the body. Different types of metals used for the ornaments mainly include silver, gold, brass, aluminum and rolled gold. Various types of semi-precious stones were also used in traditional jewelry designs. Depending up on the creativity of the jewelers, many designs were available in each type of jewelry. The information about different types of traditional ornaments worn on different body parts was collected from the respondents of Lambadi and Koya tribes. The local names along with the general names of the ornaments are given in the Table 1 and Table 2. The photographs of ornaments are shown from Figure 1 to 30. The ornaments used for various parts of the body are as follows:

Kaniya: Kaniya was also called as ghogrichotla. kaniya was a silver forehead ornament which decorates either sides of the parted hair as shown in Figure 1. A silver pendant called kunicha was attached to these chains in between the partition of hair. Few Lambadi women use kunicha alone without using kaniya as shown in Figure 2.

Bhooria: Bhooria was a pure gold nose ring worn by Lambadi women as shown in Figure 3 and 4. Lambadi women start to wear bhooria at the time of marriage and it was considered as a symbol of marital status and honour of a women.

Buli: Buli was a golden nose stud used by Lambadi women as shown in Figure 4. There were a wide range of buli which regards to its size and design. Women use to have these designs as per the availability in their local markets.

Vepakayalu: Vepakayalu were a set of three rings of pure gold worn by Koya women as shown in Figure 5.

Diddulu/ Thametlu: Diddulu were the golden ear rings worn by Lambadi women as shown in Figure 6, whereas Thametlu were the gold or rolled gold ear rings worn by Koya women as shown in Figure 7.

Har: Har was a silver coins necklace which was worn by Lambadi bride at the time of marriage and it represents the marital status of Lambadi women. The photograph of har is shown in Figure 13. 
Table.1 Lambadi ornaments used for different parts of the body

\begin{tabular}{|c|l|c|c|}
\hline S. No & Name of the ornament & Body part & Metal \\
\hline 1 & Kaniya & Fore head & Silver \\
\hline 2 & Kuniche & Fore head & Silver \\
\hline 3 & Topli & hair & Silver \\
\hline 4 & Bhooria & Nose & Gold \\
\hline 5 & Buli & Nose & Gold \\
\hline $\mathbf{6}$ & Diddulu & Ear & Gold \\
\hline 7 & Har & Neck & Silver \\
\hline $\mathbf{8}$ & Cheed & Neck & Silver \\
\hline 9 & Kante & Neck & Silver \\
\hline 10 & Hasla & Neck & Silver \\
\hline 11 & Lallihar & Neck & Beads \\
\hline 12 & Nallapoosalu & Neck & Beads and gold \\
\hline 13 & Waukdo & Ankle & Brass \\
\hline 14 & Khass & Ankle & Brass \\
\hline 15 & Gode & Ankle & Brass \\
\hline 16 & Mettelu & Toe & Silver \\
\hline 17 & Baliya & Upper arm & Ivory \\
\hline 18 & Panchela & Lower arm & Ivory \\
\hline 19 & Winte & Fingers & Silver \\
\hline 20 & Champapinnulu & Hair & silver \\
\hline
\end{tabular}

Table.2 Koya ornaments used for different parts of the body

\begin{tabular}{|c|c|c|c|}
\hline S. No & Name of the ornament & Body part & metal \\
\hline 1 & Baasikam & Fore head & Rolled gold \\
\hline 2 & Vepakayalu & Nose & Gold \\
\hline 3 & Thametlu & Ear & Gold/brass \\
\hline 4 & Patteda & Neck & Beads and gold \\
\hline 5 & Poosaladanda & Neck & Beads \\
\hline 6 & Patteelu & Ankle & Silver / steel \\
\hline$\overline{7}$ & Kallakadiyalu & Ankle & Silver \\
\hline 8 & Mettelu & Toe & Silver \\
\hline 9 & Gajulu & Arms & Glass \\
\hline 10 & Chethikadiyalu & Arms & Silver \\
\hline 11 & Ungaralu & Fingers & Rolled gold / Gold \\
\hline
\end{tabular}




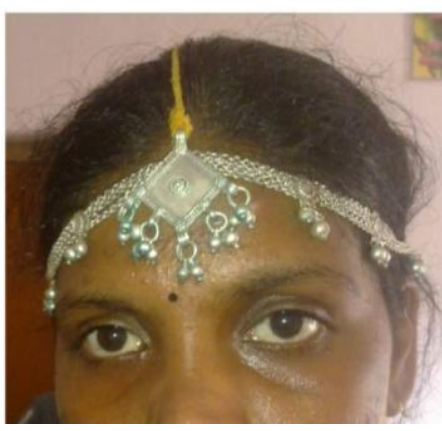

Fig:

1.KaniyaandKunicha

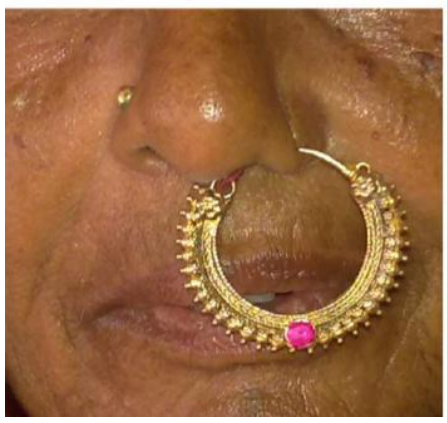

Fig: 4. Buliand Bhooria

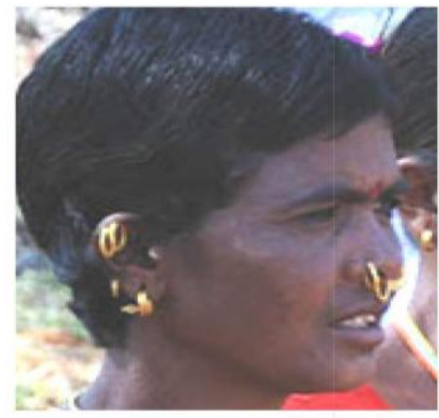

Fig: 7. Koya woman wearing Thametlu

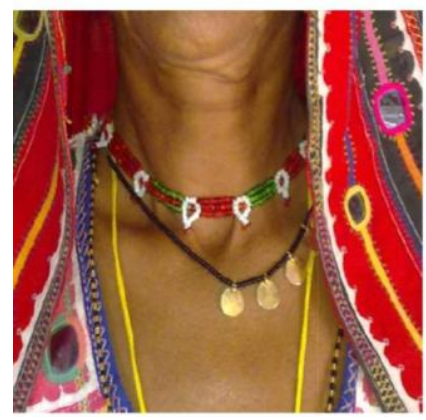

Fig: 10. Lallihar,

NecklaceandNallapoosalada

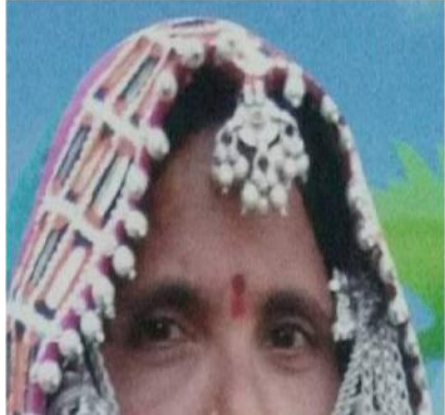

Fig: 2. Lambadi woman wearing Kunicha

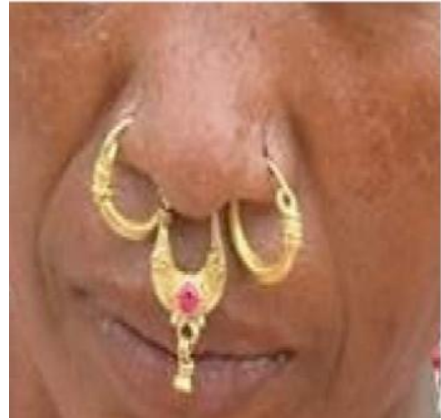

Fig: 5. Vepakayalu

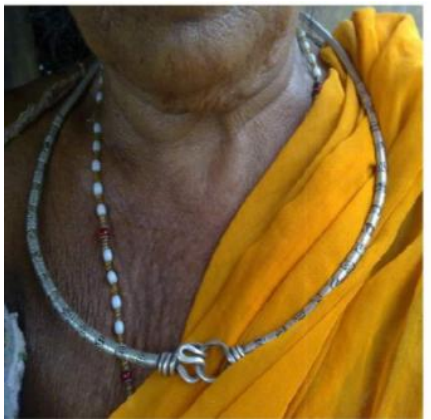

Fig: 8. Lambadi woman wearing Kante

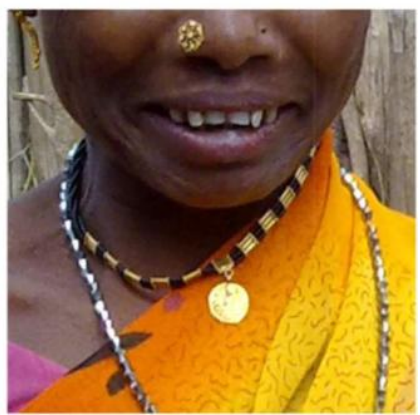

Fig: 11. Koya woman wearingPatteda

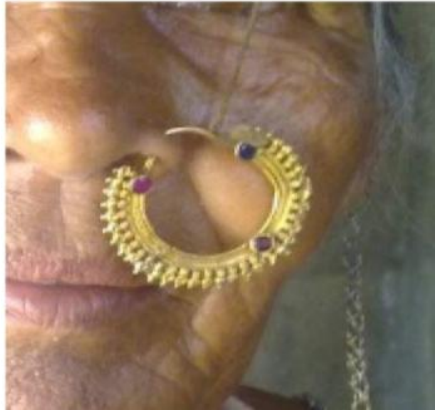

Fig: 3. Bhooriya

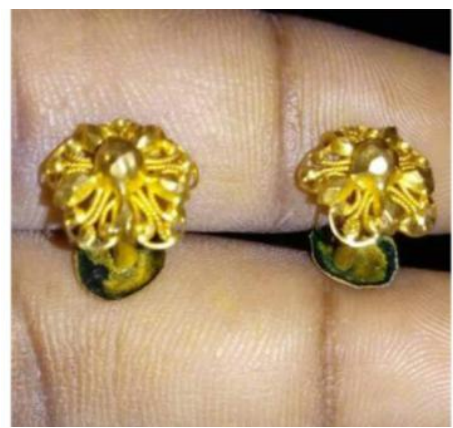

Fig: 6. Lambadi Diddulu

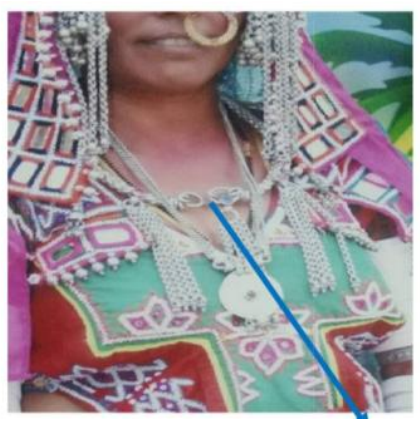

Fig: 9. Lambadi woman wearing Hasla

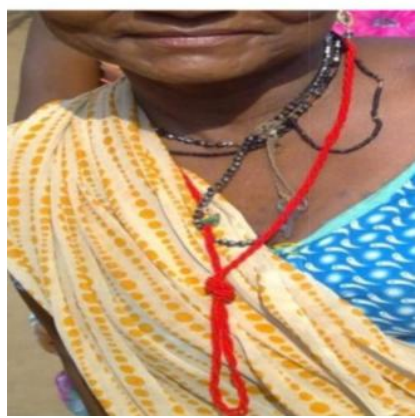

Fig: 12. Koya woman wearing Poosaladanda 


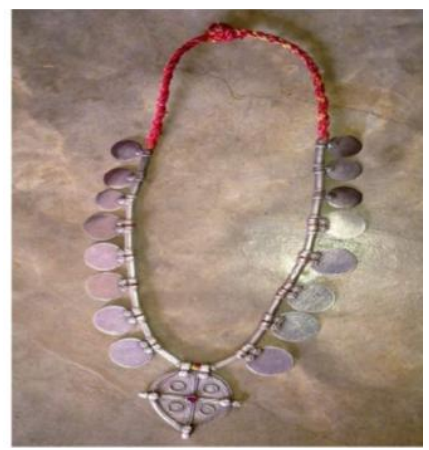

Fig: 13. Lambadi Har

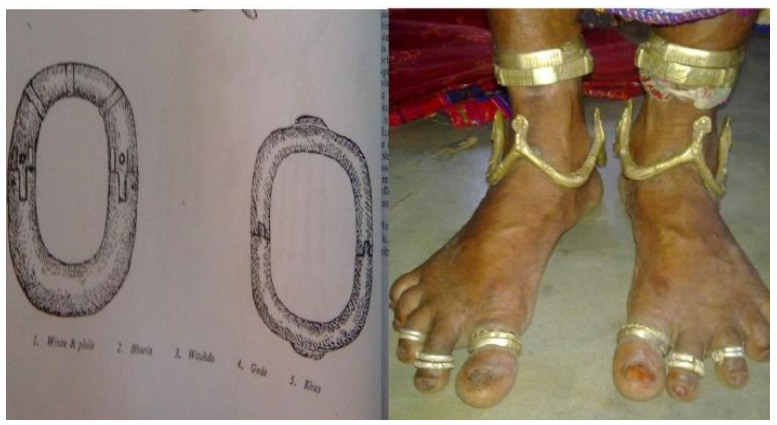

Fig: 15. Lambadiwoman wearing Waukdo, Khass, Gode, Mettelu

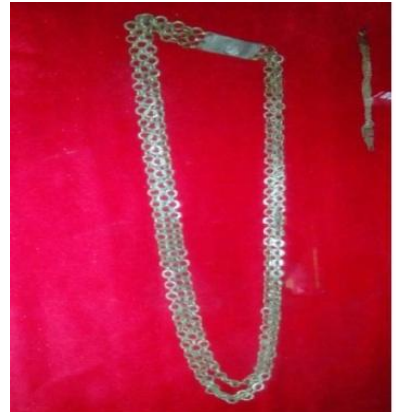

Fig: 14. Lambadi Cheed

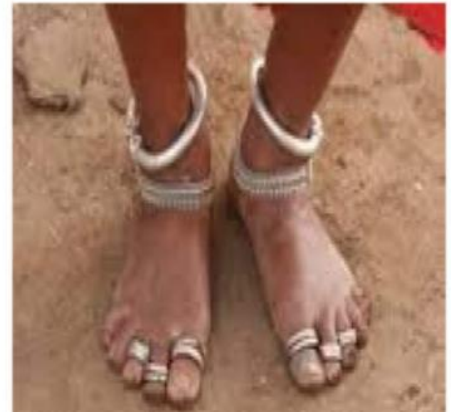

Fig: 16. Koya woman wearing KallaKadiyalu, Patteelu and Mettelu

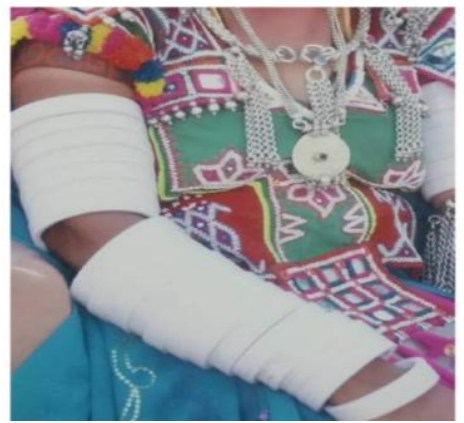

Fig: 17. Lambadi woman wearing Baliya and Panchela

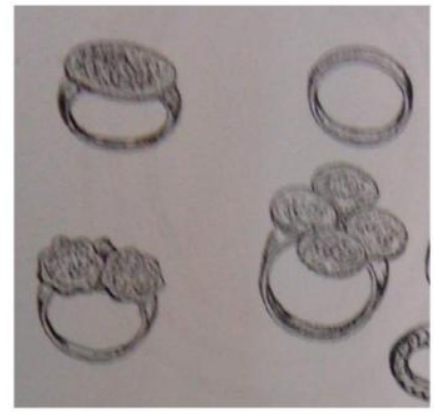

Fig: 20. Lambadi Winte with silver coin

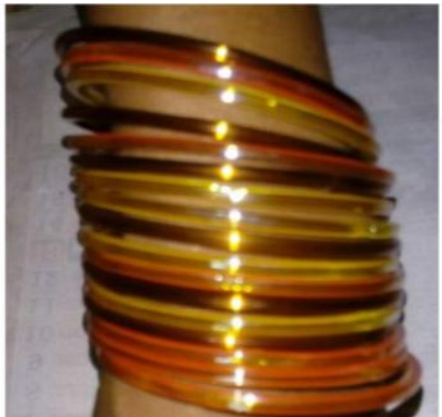

Fig: 18. Koya woman wearing Gajulu

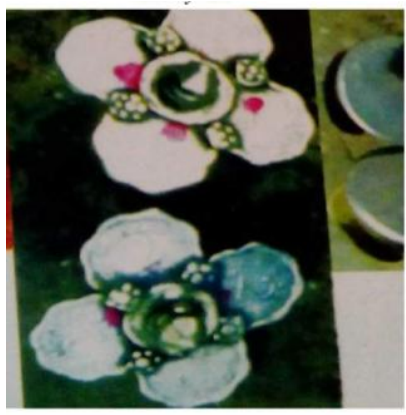

Fig: 21. Lambadi Winte with four silver petals

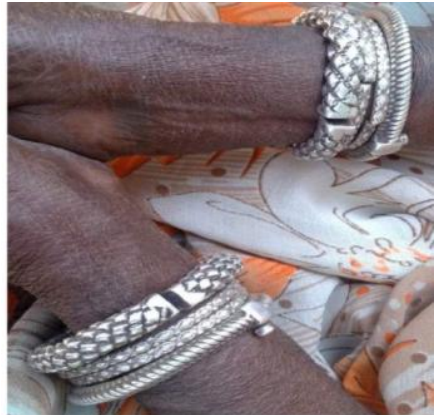

Fig: 19. Koya woman wearing ChethiKadiyalu

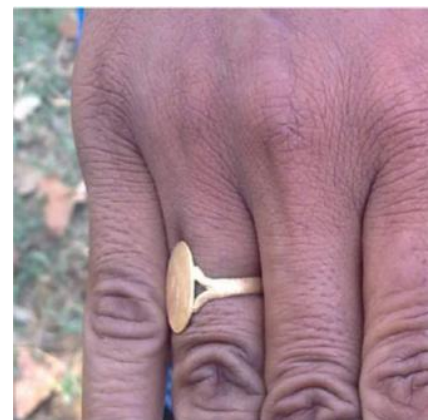

Fig: 22. Koya woman wearing Ungaralu 


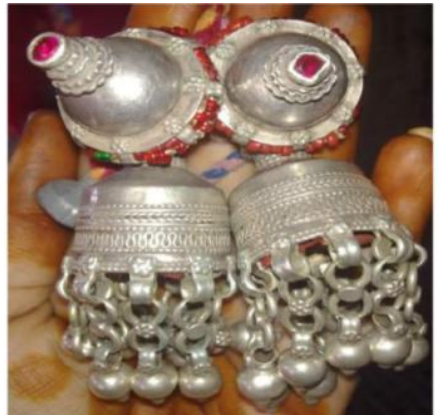

Fig: 23. Topli of Lambadi woman

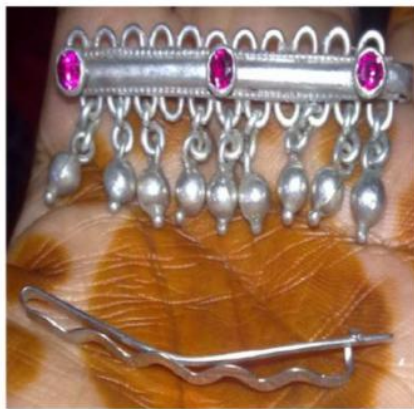

Fig: 26. Champapinnulu of Lambadi woman

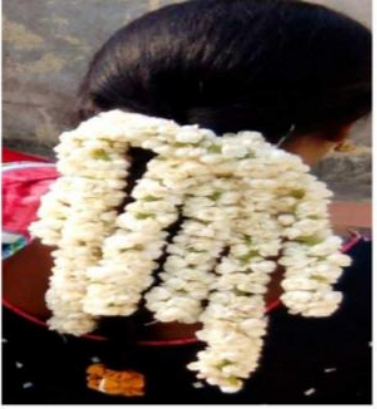

Fig: 27. KoyaPoolaJeda adorned with flowers
Fig: 24. Champapinnulu worn by Lambadi woman

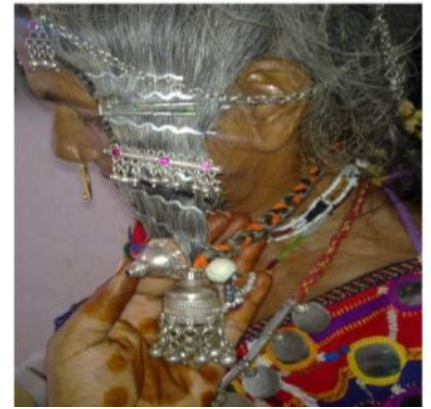

Fig: 25. Topliworn by Lambadi woman
Cheed: Cheed was a group of three silver chains attached with a single hook and it was worn by Lambadi married women. The photograph of cheed is shown in Figure 14.

Kante and hasla: Kante was a stiff silver ornament worn by Lambadi women around the neck with the help of hook as shown in the Figure 8. Kante was a plain ring like structure, whereas, Haslawas also a stiff silver ornament worn around neck, but few silver chains were suspended from the ring at three regular intervals as shown in Figure 9.

Lallihar: Lallihar was worn by Lambadi married women and the design of it was shown in Figure 10. Itwas a type of necklace made up of beads. Various geometric forms of designs were made by using different bright colored beads.

These geometric motifs were arranged at regular intervals on a string made up of beads.

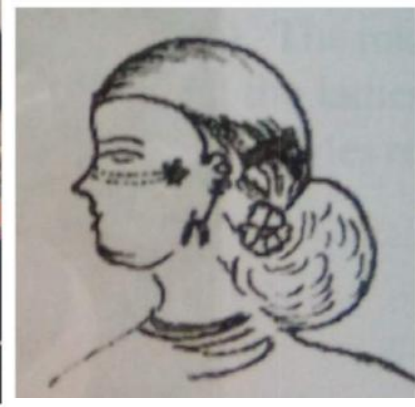

Fig: 28. KoyaMudi

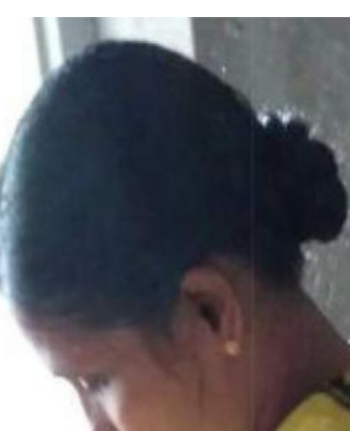

Fig: 29. Lambadi Mudi
Nallapoosaladanda

/ Patteda: Nallapoosaladanda was a black beaded mangalasutra worn by married women of both Lambadi and Koyawomen. Gold coins or pendants were used in the middle of this nallapoosaladanda as shown in Figure 10 and 11. It was called as patteda by Koya women.

Poosaladanda: Poosaladandawas a colorful beaded necklace without the use of any pendants or coins. It was worn by unmarried and married females of Koya tribe. The image of poosaladanda is shown in Figure 12.

Waukdo: Waukdo were the brass anklets worn by Lambadi bride at the time of marriage. These anklets were made in scalloped shape arrangement as shown in Figure 15.

Gode and Khass: Gode and Khasswere the brass anklets worn just above waukdo by Lambadi women as shown in Figure 15. Gode was worn above waukdo whereas khass was 
worn above gode. Khassand godewere closed and opened with the help of screw while using.

Patteelu and kallakadiyalu: Patteelu and kallakadiyalu were the silver ankle ornaments worn by Koya female as shown in Figure 16. Patteelu were the flexible chain like ornaments which were arranged with jingling ghungurus, whereas kallakadiyalu were the stiff silver ornaments which can be opened and closed with the help of screw while using.

Mettelu: Mettelu were the toe rings worn by both Lambadi and Koya women. These are simple ring like structures but occasionally mettelu with floral patterns and with small ghugurus were also used. Most of the women use more than one mettelu as shown in Figure 15 and 16.

Baliya and Panchela: Baliya were the ivory bangles worn by Lambadi women in their upper arm to show the marital status of the women. These are nine in number and worn only by married women. Panchela were the ivory bangles worn on the fore arm. There is no limitation in number for panchela as shown Figure 17.

Gajulu: Gajulu were the ordinary glass bangles worn by both unmarried and married women of Koya tribe. The image of gajulu was shown in Figure 18.

Chethikadiyalu: Chethikadiyalu were the silver thick bangle like ornaments worn by Koya women. Various geometric designs such as lines, rhombus, pentagons, dots etc, were engraved on these chethikadiyalu as shown in Figure 19. Few women of Koya were wearing aluminum chethikadiyalu instead of silver.

Winte: Winte was the finger ring worn by Lambadi women. The simple ring was fixed with plain silver coin as shown in Figure 20.
Four flower petals pattern was also used instead of coin as shown in Figure 21. Number of rings on each hand depends on the economic condition of the family.

Ungaralu: Ungaraluwere the metallic finger rings worn by men and women of Koya tribe. It was a simple ring without any elaborate carved design as shown in Figure 22.

Champapinnulu: Champapinnulu were the hair pins or hair ornaments used by Lambadi women. These are made up of silver and semi- precious stones as shown in Figure 26. Various floral motifs and ziz-zag patterns were created on the champapinnulu using silver metal. These champapinnulu were fixed over the plaits that were hanged on both side of the head as shown in Plate 16 image $\mathrm{C}$.

Topli: Topli were the silver hair ornaments tied at the ends of parted hair by Lambadi women as shown in Plate 16 image D. Topli was an ear ring like ornament with a big stud and bell shaped hanging. These are engraved with geometrical designs and decorated with semi-precious stones. Whereas the hanging bell was also engraved with various geometrical designs like line, zig-zag patterns, circles etc, and ghunghurus were attached around the edges of the bell as shown in Figure 24.

\section{Hair styles of tribal women}

\section{Lambadi hair styles}

Lambadi hairstyle was very unique than any other tribes. Firstly, the hair in the crown portion was parted in two and it was plaited. The end of plaits was finished with fabric string having topli at the ends as shown in Figure 25. They part the hair sideways, so that the hair along with topli falls on the cheeks. The parted and hanging portion of hair was beautifully decorated with silver 
champapinnulu as shown in Figure 24. The remaining hair at the back was pleated along with topli's fabric string. The plaited hair was called as jeda. The old Lambadi women usually make a bun at the back which was called as mudi is shown in Figure 29.

\section{Koya hair styles}

The old Koya women used to make a mudi (bun) at the back as shown in Figure 28. The younger generation of Koya make plait of their hair and decorated with forest flowers especially during ceremonies and marriage events which was called as poolajeda as shown in Figure 27.

Ornaments have been made to beautify nearly for every body part, from hairpins to toe rings. Ethics of beauty vary greatly from one tribe to another tribe, an ornament worn as a necklace could be worn on to the head by the other tribe. In the present study I explored what kinds of ornaments were worn by the ancient tribals and how they preserved till this generation in indigenous way. It was observed that, many of the Lambadi's are selling off their silver ornaments due to their poor economic status. If Government run some welfare programme to help them in their profession, it will be helpful to improve their economic stability. So, that they will be more interested in preserving their valuables to show it to the younger generations They can also be allowed to work on designing and making ornaments, as they have their unique form of jewelry. It is also suggested that these ornament designs can be incorporated in designing textiles like structural designing and printing.

\section{References}

Dwivedi, D. J. (2016). Indian Tribal Ornaments; a Hidden Treasure. Journal of environmental science, 3.

Nelson, R. (1993). Ornament: An Essay Concerning the Meaning of Decorative Design. Fitzroy, Victoria: Craft Victoria.

\section{How to cite this article:}

Godi Sindhu and Shahnaz Jahan. 2018. Traditional Ornaments of Lambadi and Koya Women. Int.J.Curr.Microbiol.App.Sci. 7(11): 684-691. doi: https://doi.org/10.20546/ijcmas.2018.711.081 